\title{
Incertidumbre ante los nuevos escenarios migratorios. Transformaciones recientes en la migración en tránsito en Costa Rica*
}

\section{The uncertainty of new migratory scenarios. Recent transformations in transit migration in Costa Rica}

\author{
María José Chaves Groh** \\ Centro Centroamericano de Población, Universidad de Costa Rica, San José, Costa Rica.
}

\section{Resumen}

Costa Rica se ha identificado históricamente como el principal receptor de migración en la región centroamericana. Sin embargo, a partir del año 2009 se empiezan a identificar importantes transformaciones en el escenario de tránsito que desembocan en dos importantes emergencias: la primera en noviembre de 2015 con la llegada masiva de personas cubanas y la segunda en abril de 2016 con la llegada de personas originarias de diferentes países del Caribe, África y Asia. A partir del análisis de notas de prensa, de la revisión de informes de situación de instituciones vinculadas con la atención de estas emergencias y de entrevistas a actores clave, se han identificado los principales desafíos que enfrentó el Estado costarricense en la atención de estas emergencias y se analizan las transformaciones registradas en el escenario migratorio de tránsito. Como resultado de este proceso investigativo se concluye que el país debe repensar su política migratoria desde un enfoque prospectivo y versátil, trascendiendo

* Este artículo es resultado del proyecto de investigación: "Mismos derechos, diferentes realidades: migración de tránsito y de destino en Costa Rica".

** Magíster en Gestión del Riesgo a Desastres y Atención de Emergencias, Universidad de Costa Rica, y bachiller en Sociología, Universidad Nacional. Investigadora en el Centro Centroamericano de Población de la Universidad de Costa Rica. Dirección postal Centro Centroamericano de Población: San José 2060, Costa Rica. Correo electrónico: maria.chavesgroh@ucr.ac.cr

Cómo citar este artículo: Chaves, M. (2020). Incertidumbre ante los nuevos escenarios migratorios. Transformaciones recientes en la migración en tránsito en Costa Rica Si Somos Americanos. Revista de Estudios Transfronterizos, 20(1), 33-54. doi: 10.4067/S0719-09482020000100033 
su especialización en la inmigración y asumiendo de forma integral el papel que le corresponde en el entramado migratorio regional.

Palabras clave: migración internacional, migración de tránsito, Costa Rica.

\begin{abstract}
Costa Rica has historically been identified as the main destination country of migration in Central America. However, from 2009 onwards, important changes were observed in the migration scenario which have led to two major emergencies: the first in November 2015 with the massive arrival of Cuban citizens and the second in April 2016 with the arrival of people from various Caribbean, African and Asian countries. This work is based on an analysis of news articles, a review of reports on this situation issued by institutions linked to the response to these emergencies, and interviews with key actors. This analysis therefore allows us to identify the changes registered in the migratory scenario of transit to establish the main challenges faced by the Costa Rican State in its response to these emergencies. As a result of this research process, it has been concluded that the country must reassess its migration policy and adopt a forward looking and versatile approach, which transcends its focus on immigration issues and plays a comprehensive role in the regional migratory framework.
\end{abstract}

Keywords: International migration, transit migration, Costa Rica.

\title{
Introducción
}

Las migraciones hacen parte de las transformaciones sociales, políticas, económicas y culturales de nuestras sociedades, se tejen con sus crisis y sus formas de resolución; es decir, son dinámicas vivas, flexibles y adaptables. Por lo tanto, para gestionarlas también se requiere de políticas públicas que se ajusten oportunamente a ese dinamismo.

La transnacionalización de las fuentes de trabajo, el aumento de los conflictos armados, la violencia social, las crisis de los cuidados, la conformación de familias trasnacionales, el cambio climático y los desastres, hacen suponer que la necesidad de moverse de un lugar a otro será cada vez mayor. Consiguientemente, las migraciones estarán cada vez más presentes en los foros de política internacional, en los acuerdos que realicen los bloques económicos y en la cotidianidad de las familias del mundo.

En este contexto, la Organización Internacional para las Migraciones (OIM) señala que las migraciones son necesarias y deseables para responder a las transformaciones en el mundo 
del trabajo, de modo que deben gestionarse a través de políticas responsables, sensatas y humanas (Lacy citado en OIM, 2018a).

El Informe sobre las migraciones en el mundo 2018, recientemente publicado por la OIM (2018b), señala que para el año 2015 se estimaba en 244 millones el total de migrantes internacionales (OIM, 2018b, p. 3). El mismo informe indica que en 2016 había 40,3 millones de personas desplazadas internas en todo el mundo y 22,5 millones de refugiadas, y afirma que el número total de personas desplazándose ha alcanzado niveles sin precedentes (OIM, 2018b, p. 3).

Esta realidad global se expresa claramente en el contexto centroamericano. Según el "Quinto Informe del Estado de la Región" (Programa Estado de la Nación [PEN], 2016) ${ }^{1}$ para el año 2015 cerca de cuatro millones de personas centroamericanas, es decir 8\% de la población, vivían fuera de su país de origen, siendo Estados Unidos el principal receptor del $82 \%$ (Programa Estado de la Nación, 2016, p. 44). En el caso de las migraciones intrarregionales, para el año 2015 el 13\% del total de migrantes centroamericanos se quedó en la región, siendo Costa Rica destino del 64,8\% (Programa Estado de la Nación, 2016, p. 89).

En Centroamérica, Costa Rica se ha identificado históricamente como un receptor de migración. Al respecto, León, Estrada, Molina y Morales (2012) señalan que es el principal receptor de migración laboral -tanto permanente como estacional- en el istmo centroamericano. Sin embargo, Jiménez-Matarrita (2009) plantea que en este país confluyen al menos cuatro dinámicas migratorias. El movimiento Sur-Sur, representado por las personas de origen nicaragüense, panameño y colombiano que llegan al país; el movimiento Sur-Norte, representado por costarricenses que migran hacia Estados Unidos; el movimiento Norte-Sur, representado por personas estadounidenses, canadienses y europeas que vienen a radicarse al país; y el movimiento Sur-Sur-Norte, representado por personas de diferentes países que transitan por Costa Rica para llegar hasta Estados Unidos.

En los últimos años, el movimiento Sur-Sur-Norte o movimiento de tránsito, se ha reconfigurado notoriamente a partir de lo que OIM denomina flujos mixtos o mezclados, es decir, "movimientos de población complejos que comprenden solicitantes de asilo, refugiados, migrantes económicos y otros migrantes" (OIM, 2006, p. 27).

Con el fin de caracterizar las principales transformaciones que están ocurriendo en esta dinámica migratoria, contextualizarlas en el escenario internacional y proponer algunas recomendaciones que permitan adaptar el marco normativo a las transformaciones en las dinámicas migratorias actuales, especialmente en el escenario de tránsito, el Centro Centroamericano de Población de la Universidad de Costa Rica desarrolló entre los años

1 El "Informe del Estado de la Región" es elaborado periódicamente por el Programa Estado de la Nación (PEN). Este programa es coordinado por el Consejo Nacional de Rectores (CONARE), entidad que agrupa a las cinco universidades públicas de Costa Rica. 
2017 y 2018 el proyecto de investigación "Mismos derechos, diferentes realidades: migración de tránsito y de destino en Costa Rica". Este proyecto analizó los primeros movimientos migratorios masivos en tránsito que llegaron al país: el primero a partir de noviembre de 2015 y el segundo desde abril de 2016, los que generaron una importante emergencia a nivel institucional y en las comunidades donde se albergaron.

Este artículo recoge los principales hallazgos del proceso investigativo y los presenta en seis apartados. En la Introducción, se contextualiza la investigación desarrollada y los alcances del artículo. En el número 1, se describe la estrategia metodológica utilizada para la investigación; en el número 2 se configura el contexto internacional y nacional en que ocurren los movimientos migratorios de interés. En el número 3 se describe el alcance de la respuesta institucional y normativa para atender las emergencias migratorias. En el número 4 se propone una serie de recomendaciones que apuntan a pensar políticas y acciones prospectivas que podrían implementarse a nivel regional, nacional e institucional para responder a los constantes cambios en las dinámicas migratorias. El último apartado presenta algunas reflexiones finales.

\section{Estrategia metodológica}

El periodo de estudio se inició en noviembre de 2015, momento en que las autoridades costarricenses detectaron el primer movimiento masivo de migrantes en tránsito, y finalizó en diciembre de 2016. Una vez establecido el período del estudio, se desarrolló una estrategia metodológica basada en tres líneas de trabajo: primero, una revisión bibliográfica que incluyó una revisión de la prensa escrita, ${ }^{2}$ investigaciones recientes relacionadas con temas migratorios, además de legislación e informes de situación de las instituciones involucradas en la atención de inmigrantes. La segunda línea de trabajo correspondió a la recopilación de información primaria a partir de entrevistas semiestructuradas a 19 informantes clave, entre los cuales estaban representantes de organismos internacionales, de instituciones públicas y gobiernos locales que tuvieron a su cargo la atención de las personas migrantes en tránsito en el momento de la emergencia. En el proceso de entrevistas se recolectó información sobre la historia migratoria de la zona, el perfil de las poblaciones migrantes, las fortalezas y debilidades del quehacer institucional e interinstitucional en la atención de las emergencias migratorias y recomendaciones para adaptar el marco normativo del país a las transformaciones en las dinámicas migratorias analizadas. Por último, una vez realizadas y transcritas las entrevistas, se desarrolló la tercera línea de trabajo que consistió en el análisis de la información a partir de los objetivos planteados en esta investigación.

2 Esta revisión abarcó el período 2014-2017. Se incluyó el año 2014 para identificar si en ese año se reportó algún evento migratorio previo a la emergencia de noviembre de 2015. La síntesis de prensa se puede consultar en http://hdl.handle.net/10669/76532 


\section{Contextualización del estudio}

Diversas razones han convertido a Costa Rica en el principal receptor de inmigración de Centroamérica, sobre todo de personas nacidas en Nicaragua, quienes representan el 75,5\% de la población inmigrante que radica en el país y el 9,28\% del total de la población en Costa Rica (Instituto Nacional de Estadística y Censos, 2018).

La importancia que tiene el corredor Nicaragua-Costa Rica se refleja en la legislación migratoria costarricense, en sus políticas públicas, en la investigación académica, en la oferta de servicios que brinda la institucionalidad y en el acompañamiento que ofrecen las organizaciones sociales. Es decir, el país se ha especializado en responder a una dinámica migratoria específica; sin embargo, desde mediados del siglo XX la inmigración se ha complejizado, ${ }^{3}$ la emigración ha cobrado fuerza y se han diversificado las dinámicas que ocurren en el escenario de tránsito migratorio.

Para comprender y dimensionar el alcance de estas transformaciones, a continuación, se describe el contexto internacional y nacional en el cual ocurren los dos movimientos migratorios masivos en tránsito que resultan de interés para este artículo.

\subsection{Contexto internacional del primer movimiento migratorio masivo en tránsito. La llegada de personas cubanas}

En enero de 2012, el Gobierno cubano flexibilizó las condiciones para que las personas de esa nacionalidad accedieran con mayor facilidad a documentos migratorios (OIM, 2016). Posteriormente, en diciembre de 2014, con el restablecimiento de las relaciones diplomáticas entre Estados Unidos y Cuba, en la isla se empezó a rumorar que la política "pies secos, pies mojados"4 podría ser derogada por el entonces presidente Barak Obama, razón por la cual miles de personas migraron hacia Estados Unidos, llegando en avión a Ecuador $^{5}$ y de ahí continuaban el viaje por tierra a través de las redes de tráfico de personas. ${ }^{6}$

El 10 de noviembre de 2015, el Gobierno costarricense desarticuló una importante red de tráfico de personas, con lo cual miles de migrantes que iban en tránsito desde Ecuador hacia Estados Unidos se quedaron sin el soporte que les brindaba para moverse sin ser detectados

3 Además de la inmigración nicaragüense, ha aumentado la inmigración procedente de otros países latinoamericanos, la de países de renta alta, la de países asiáticos y la inmigración estacional indígena (Dirección General de Migración y Extranjería, 2017).

4 En 1995, el Gobierno de Estados Unidos modificó la Ley de Ajuste Cubano (Cuban Adjustment Act o CAA) vigente desde 1966, e implementó la política "pies secos, pies mojados". Esta política permitía a personas cubanas que ingresaban por tierra a territorio estadounidense optar por la residencia permanente, mientras que las que fueran interceptadas en el mar serían deportadas a Cuba.

5 Desde el año 2014 hasta el 1 de diciembre de 2015, Ecuador otorgó visas hasta por tres meses a las personas cubanas, sin solicitarles carta de invitación (Organización de Estados Americanos y Organización Internacional para las Migraciones, 2016)

6 La política de "pies secos, pies mojados" fue derogada en enero de 2017. 
por las autoridades migratorias. Con la desarticulación de esta red quedó en evidencia la magnitud del movimiento, que pasó de 2.548 personas en 2013 a 10.651 en 2015 (Ministerio de Planificación Nacional y Política Económica, 2018).

A pesar de que las personas cubanas tienen visa restringida para ingresar a Costa Rica, desde el 13 de noviembre de 2015 el Gobierno empezó a otorgar un salvoconducto que les permitía transitar por el país de forma regular y continuar su viaje hacia Nicaragua. No obstante, el Gobierno nicaragüense cerró el paso fronterizo para las personas migrantes en tránsito, generando una importante crisis en la frontera norte de Costa Rica, donde diariamente aumentaba la concentración de personas que querían seguir hacia su país de destino. Desde ese momento, los gobiernos de Nicaragua y Costa Rica no han restablecido ningún tipo de coordinación relacionada con la migración en tránsito ${ }^{7}$.

En este contexto, el Gobierno costarricense ensayó diferentes alternativas diplomáticas (convocatoria del Sistema de Integración Centroamericano, reuniones bilaterales con los países, solicitud de apoyo a la Organización de Estados Americanos, entre otros), de las cuales solo tuvo éxito con la propuesta de establecer un "corredor aéreo" con los gobiernos de El Salvador, Guatemala y México. Como resultado de este "corredor aéreo", las y los migrantes llegaban a México y de ahí seguían el viaje hacia Estados Unidos. Entre el 13 de enero y el 15 de marzo de 2016, este plan se puso en marcha y habilitó siete vuelos hacia El Salvador (desde ahí las personas seguían a México en autobús), y 28 vuelos directos a México (Organización de Estados Americanos [OEA] y Organización Internacional para las Migraciones [OIM], 2016).

\subsection{Contexto internacional del segundo movimiento migratorio masivo en tránsito: las personas extracontinentales}

En enero de 2010, Haití -el país más empobrecido de América- sufrió el terremoto más importante desde 1770, catástrofe que dejó más de doscientos mil fallecidos y tres millones de desplazados (Cavaletto, 2012). En este contexto, la Guyana Francesa -principal destino de las personas haitianas en América del Sur "por la afinidad lingüística, cultural y étnica y por la promesa que los traficantes los llevarían a Francia y a Europa" (OEA y OIM, 2016, p. 22)- cerró sus fronteras, por lo que miles de personas haitianas debieron migrar hacia otros destinos de América del Sur, entre ellos Chile, Ecuador y Brasil.

Concretamente, en el caso de Brasil el Consejo Nacional de Inmigración (CNI) de este país aprobó tres directrices para la atención del movimiento migratorio haitiano. Primero, en marzo de 2011 dictó la Resolución Recomendada № 08/06, que concedía residencia

7 Si bien en términos formales la frontera norte permanece cerrada, lo cierto es que miles de migrantes en tránsito consiguen cruzarla de forma irregular, enfrentando grandes riesgos debido a los traficantes que les utilizan para el contrabando de bienes o drogas, teniendo que pagar extorsiones a las autoridades nicaragüenses y exponiendo seriamente sus vidas. Ver notas en prensa en:

https://www.nacion.com/sucesos/seguridad/migrantes-que-sobrevivieron-a-naufragio-habian-dejado-

albergue-en-la-cruz/GCNYOOYZWNCVNBCW453WMRZBGU/story/ 
permanente a las personas haitianas por razones humanitarias (Nieto, 2014). Posteriormente, en enero de 2012 aprobó la Resolución Normativa $N^{\circ}$ 97, con la cual buscaba ordenar este movimiento migratorio, estableciendo un límite de 1.200 permisos anuales (Nieto, 2014). Finalmente, el 29 de abril de 2013 el CNI revocó ese límite y permitió el ingreso sin restricción de personas haitianas (Resolución Normativa 102/2013) (Nieto, 2014).

Como resultado de estas resoluciones, en el período 2010-2015 Brasil autorizó 43.871 visas humanitarias a personas haitianas (OEA y OIM, 2016). Esta visa era renovable a los seis meses y posteriormente permitía solicitar la residencia por cinco años (Nieto, 2014).

Cabe destacar que en este período Brasil tuvo una fuerte demanda de fuerza de trabajo para la construcción de infraestructura por ser sede del Mundial de Fútbol masculino en 2014 y de los Juegos Olímpicos de Río en 2016. De modo que la llegada de miles de personas buscando trabajo, respondía directamente a una necesidad del país. Sin embargo, pasados los eventos deportivos finalizó la construcción de infraestructura, se acabó la generación de empleos directos e indirectos, se agudizó la crisis política que dio como resultado la destitución de la presidenta Dilma Rousseff y los beneficios de la residencia estaban próximos a vencerse. Todo esto llevó a miles de personas haitianas a emprender otro proyecto migratorio, ahora hacia Estados Unidos, por lo que emprendieron rumbo transitando por territorio costarricense.

De acuerdo con la actualización de la Política Migratoria Integral de Costa Rica, realizada en el año 2018, una de las razones por las cuales el movimiento migratorio haitiano se dirigió a Estados Unidos era que este país les ofrecía un Estatus de Protección Temporal (Temporary Protected Status) para residir y trabajar (Ministerio de Planificación Nacional y Política Económica, 2018). Sin embargo, cabe destacar que además de las personas de origen haitiano, migrantes de otras nacionalidades también se vieron favorecidas con las medidas migratorias brasileras. Por ejemplo, entre el año 2010 y el año 2016 el número de personas refugiadas pasó de 3.904 a 9.952 (Comitê Nacional para os Refugiados, 2017).

\subsection{El contexto costarricense}

Como se indicó anteriormente, Costa Rica ha enfocado su legislación y su quehacer en la inmigración laboral nicaragüense, por lo tanto, las demandas que suponen otros escenarios migratorios aún representan importantes desafíos para el país y su institucionalidad.

En este sentido, para analizar la legislación migratoria de la región, Chaves, Lexartza y Carcedo (2013) propusieron una tipología basada en el enfoque que prevalece en cada política migratoria. De acuerdo con esta tipología, una primera categoría sería la que prioriza la protección de los derechos humanos como el eje vertebrador de la política migratoria (enfoque de derechos humanos). La segunda categoría se enfoca en el uso que el 
país receptor hace de las migraciones (enfoque utilitario) y la tercera categoría prioriza la seguridad nacional incluso por encima de los derechos fundamentales de las personas migrantes (enfoque securitario) (Chaves et al., 2013).

De acuerdo con esta tipología, la política migratoria costarricense se ubica en la categoría de utilitaria, al centrar la relación del Estado con las personas inmigrantes en su condición de trabajadoras, es decir, a partir de la fuerza de trabajo que aportan al país. En este sentido, Lucas destaca que, al fundamentar la legislación migratoria en criterios utilitaristas, "no solo resulta ineficaz, en virtud de su negación de la complejidad del fenómeno migratorio y de los factores que moldean los flujos migratorios (regulares e irregulares), sino también ilegítima, al generar la violación de derechos fundamentales” (Lucas cit. en Ceriani, 2011, p. 72).

En este contexto, las demandas que plantean los escenarios de origen, tránsito o retorno migratorio, no han encontrado una respuesta oportuna en el marco normativo costarricense. Concretamente en el caso de la migración de tránsito, esto se constata en la Ley General de Migración y Extranjería vigente, en la que solo hace mención a la migración en tránsito en dos oportunidades: en el Artículo 87 señala que las personas en tránsito y en tránsito vecinal fronterizo no son residentes; posteriormente, en el Artículo 144 define como permiso vecinal fronterizo el que la Dirección General de Migración y Extranjería (DGME) le otorga a personas residentes que habitan de manera regular en zonas limítrofes, para que, vía terrestre, ingresen o egresen del país con el objeto de facilitar las relaciones interfronterizas, siempre y cuando cumplan con los requisitos establecidos.

La Política Migratoria Integral, por su parte, únicamente considera la migración en tránsito en el subtema Poblaciones Vulnerables, del Eje Protección de Derechos Humanos y grupos vulnerables, donde incluye como una estrategia específica "[d]ifundir derechos y mecanismos de denuncia para las mujeres que han sido víctimas de violación a sus derechos en los tránsitos migratorios” (Consejo Nacional de Migración, 2013, p. 63).

A partir de lo anterior, es claro que los recursos normativos con los cuales contaba el Estado costarricense para diseñar e implementar acciones dirigidas a la migración en tránsito eran insuficientes. Esto se terminó de constatar en los vacíos legales y en el caos institucional que generó la llegada masiva de migrantes.

\section{Reconfiguración reciente de la migración en tránsito y respuesta del Estado costarricense}

“... esta situación de migración no va a parar, ya encontraron esta ruta y van a seguir con esta ruta, es algo que va a continuar y se va a mantener". (Cruz Roja, La Cruz, comunicación personal, 7 de julio de 2017)

Como se indicó anteriormente, Costa Rica históricamente ha sido lugar de tránsito para quienes quieren llegar a los Estados Unidos, pero también, desde las comunidades fronterizas se han recibido migrantes en tránsito que buscan quedarse en el país. De 
acuerdo con las entrevistas realizadas, en el perfil tradicional de estos migrantes destaca que se trataba de hombres - nicaragüenses que llegaban por la frontera norte y colombianos que llegaban por la frontera sur- que viajaban solos y se quedaban en comunidades fronterizas realizando trabajos ocasionales para reunir dinero y luego instalarse en San José, la capital.

A partir de 2009 esta dinámica empezó a cambiar rápidamente. Según las personas entrevistadas en ese año, se contabilizaban mensualmente aproximadamente cinco migrantes. Para el año 2011 aumentó a entre 20 y 30 personas. En este sentido, datos de la DGME y OIM confirman el significativo aumento del paso de migrantes en los años siguientes. En 2013, la coordinación policial de Paso Canoas identificó 2.071 migrantes en condición irregular. Para el 2014 fueron 4.870, en 2015 llegaron a ser 21.187 y solo entre enero y julio de 2016 se identificaron 5.936 migrantes (OEA y OIM, 2016, p. 31). La mayoría de estas personas eran hombres (el 75,3\%) de origen caribeño $(71,4 \%)^{8}$ (OEA y OIM, 2016, p. 31).

Sin embargo, también es importante mencionar que con la llegada de las personas cubanas primero y luego de las extracontinentales, ${ }^{9}$ se evidenciaron diferencias importantes entre estos dos grandes colectivos y en lo interno de estos grupos.

En el movimiento de las personas cubanas, los actores consultados señalan que estas hablaban castellano, tenían documentos de identificación, sus prácticas alimentarias eran similares a las costarricenses y se movían en grupos familiares. Estas características facilitaron su relación en las comunidades que les albergaron; además, contaban con recursos económicos que les permitió dinamizar la economía de esas comunidades.

En el movimiento de personas extracontinentales, todas se presentaban como africanas, asumiendo que esto impediría su deportación. Sin embargo, unas semanas después de su llegada, se constató que la mayoría procedía de Haití, incluso algunos habían nacido en República Dominicana y eran descendientes de haitianos, por lo que no contaban con registro de nacimiento en ningún país (OIM, 2016). En relación con la composición familiar, el colectivo de personas de origen africano y asiático estaba conformado sobre todo por hombres solos (a lo sumo llegaban parejas), mientras que en el colectivo haitiano era más común encontrar grupos familiares.

Otro aspecto importante de destacar es que en este movimiento migratorio había grandes diferencias idiomáticas (algunas personas hablaban creole, otras francés, otras wólof, inglés, portugués, entre otros), alimentarias, religiosas y culturales. Para la

8 Sobre todo de origen cubano, quienes representaban el 99,9\% del total de personas caribeñas (OEA y OIM, 2016).

9 Se entiende como migrantes extracontinentales o extrarregionales a las personas migrantes que provienen fuera del continente americano, en particular de África y/o de Asia (Narváez Gutiérrez cit. en Ministerio de Planificación Nacional y Política Económica, 2018). 
institucionalidad, esto representó un desafío adicional, ya que esas diferencias generaban fuertes tensiones en lo interno del colectivo de migrantes y entre ellos y el personal de las instituciones. Para atenuar estas tensiones primero se improvisaron medidas y luego tuvieron que diseñar y brindar respuestas diferenciadas comprendiendo los contextos sociales, políticos y religiosos de las personas migrantes. De acuerdo con las personas entrevistadas, tales tiranteces se expresaron en diferentes ámbitos; por ejemplo, quienes venían de países africanos y asiáticos no simpatizaban con el colectivo haitiano, por lo que usualmente optaban por permanecer en espacios separados. En el ámbito religioso había personas de diferentes denominaciones: cristianas, musulmanas, vuduistas, ${ }^{10}$ entre muchas otras, lo cual generaba burlas, temores y discriminaciones entre ellas.

ellos antes de hacer la oración llegan y se lavan los pies y las manos, pero resulta que en la misma donde hacían eso se lavan los trastes, y viera que hubo un conflicto de eso, porque ellos decían -los haitianos- decían que cómo hacía eso, que era un cochino, pero es que lo hacían (...) para asearse y después ir hacer la reverencia. (Cruz Roja, La Cruz, comunicación personal, 7 de julio de 2017)

A partir de lo anterior destacan cuatro indicadores que dan cuenta de importantes transformaciones que ocurrieron en el escenario de tránsito con la llegada de estos movimientos migratorios. Primero, cambió el carácter de lo transitorio: antes las personas pasaban por comunidades fronterizas mientras se acercaban a San José, en cambio ahora atraviesan el país de sur a norte para llegar a Estados Unidos. Segundo, este movimiento dejó de ser casi imperceptible para convertirse en un movimiento masivo; tercero, se diversificaron los orígenes nacionales y cuarto, se diversificaron también los perfiles de las personas migrante

\subsection{Respuesta política del Estado costarricense}

Ante los cambios que ocurrían en las fronteras, las autoridades locales procedieron a informarlos al nivel central de las diferentes instituciones. Sin embargo, -según señalan las personas entrevistadas- este llamado de atención no tuvo respuesta oportuna.

En 2013 cuando el movimiento de personas cubanas empezó a ser masivo, las autoridades de la DGME en la frontera sur entregaban un acta de control migratorio citando a las personas en Oficinas Centrales para que expusieran su caso e iniciaran el proceso de regularización. De acuerdo con esta fuente, entregaban 70 actas por día. Entre 2014 y 2016 ya eran 100 y en 2015 llegaron a ser 300. Sin embargo, las personas recibían el documento, pero no acudían a la citación y continuaban el viaje apoyadas en la red de tráfico. Por lo tanto, en Oficinas Centrales tampoco se pudo constatar la magnitud del movimiento que reportaban las autoridades locales.

10 Practicantes del vudú. 
En noviembre de 2015, cuando se desarticuló la red que les estaba moviendo, quienes tenían el acta de control migratorio llegaron a las Oficinas Centrales y ahí las autoridades de la DGME dimensionaron la magnitud del movimiento que desde hacía muchos meses se vivía, tanto en la frontera norte como en la frontera sur.

De parte de las autoridades no hubo una respuesta porque lo veían a nivel micro, o sea mínimo ingreso porque no llegaban las personas que citábamos, sino que pasaban directo. Hasta el día en que empezaron a llegar [las personas migrantes a las oficinas centrales de la Dirección de Migración] vieron que era una realidad lo que estaba pasando en frontera. (DGME, Paso Canoas, comunicación personal, 23 de octubre de 2017)

Frente a este contexto, la respuesta del gobierno central fue contradictoria. Primero la decisión fue hacer rechazos en la frontera, lo cual generó caos en términos normativos y en la respuesta institucional inmediata. En términos normativos, porque las personas no se podían rechazar a Panamá ante la imposibilidad de demostrar que provenían de ese país (ingresaban y salían de forma irregular) ${ }^{11}$. Además, si bien Panamá les permitió el paso hacia Costa Rica, previendo posibles rechazos, prohibió que pudieran reingresar a su territorio (Ministerio de Planificación Nacional y Política Económica, 2018). En términos de respuesta institucional, hacer rechazos en frontera suponía una importante inversión para reforzar la frontera con oficiales de la Fuerza Pública y antimotines. El resultado inmediato de estas medidas fue que, en pocos días, cientos de personas se aglomeraron en la frontera, con hambre y enojadas. Ante esta situación, el Gobierno costarricense debió permitir el ingreso de las personas migrantes al territorio nacional, generando incertidumbre y confusión en las instituciones locales que debieron cambiar rápidamente sus protocolos de actuación para atender a las personas y buscar estrategias para lidiar con la tensión generada en los días anteriores. Así queda de manifiesto en la siguiente cita: "Esta situación generó en Paso Canoas mucho caos y una acumulación enorme de personas, pero también cambios en las políticas migratorias, inicialmente rechazando a estos cubanos y posteriormente aceptándolos y ayudándoles en su ruta” (Ministerio de Salud, Paso Canoas, comunicación personal, 25 de octubre de 2017).

A partir de lo anterior, las personas entrevistadas en las instituciones locales señalan que en el nivel central se tomaron decisiones sin considerar la información, las propuestas y el trabajo que desde el nivel local se estaba realizando desde que detectaron el aumento en el movimiento migratorio. En su lugar, el gobierno central creó una figura de coordinación para articular todas las tareas desde Casa Presidencial con la institucionalidad -a nivel central y a nivel local. Esa labor fue asumida por el entonces ministro de Comunicación.

11 El Artículo 64 de la Ley General de Migración y Extranjería define rechazo como la acción "mediante la cual se niega a una persona extranjera su ingreso al territorio nacional y ordena su traslado inmediato al país de origen o procedencia, o a un tercer país que la admita". 
Todas las decisiones que provocaron aspectos positivos o negativos fueron de Gobierno Central, inclusive aquí tenemos un grupo de instituciones binacionales que trabajamos en coordinación para dar atención y protección a las personas migrantes en condiciones de vulnerabilidad y durante toda esa temporada no podíamos sesionar porque las decisiones se tomaban en Ciudad Panamá y en San José. (Ministerio de Salud, Paso Canoas, comunicación personal, 25 de octubre de 2017)

En relación con la atención directa de las personas migrantes cubanas, a partir del 16 de noviembre de 2015 se habilitaron albergues, primero en La Cruz, luego en San Ramón, Guatuso y Bijagua de Upala. En total llegaron a funcionar 32 albergues simultáneamente. Todos contaban con baños, electricidad, agua potable, cocinas, etc. y estaban debidamente habilitados por la Comisión Nacional de Prevención de Riesgos y Atención de Emergencias (CNE). Sin embargo, para la atención de las personas extracontinentales la situación fue muy diferente. Primero porque el Gobierno decidió no volver a habilitar albergues en centros poblados para evitar tensiones entre las personas migrantes y las comunidades, y segundo, porque las autoridades municipales tampoco estaban dispuestas a recibir migrantes nuevamente.

Frente a esta situación, cuando las personas extracontinentales se vieron en la frontera con Nicaragua imposibilitadas de continuar su viaje, instalaron un campamento improvisado en un lote baldío - conocido como parqueo Deldú- en Peñas Blancas, lugar que carecía de condiciones mínimas de salubridad. Ante esto, las autoridades gubernamentales consideraron imprescindible la intervención del Estado para resguardar la vida y la salud, tanto de las personas migrantes como de las nacionales.

Para implementar esta intervención, el Gobierno habilitó el primer Centro de Atención Integral al Migrante (CATEM) en Golfito, el 21 de abril de 2016. El 23 de abril abrió otro en Buenos Aires, especializado en la atención de las personas menores de edad y sus familias, y por último abrió uno en Peñas Blancas. De esta forma, las personas que iban llegando se ubicaban -de acuerdo con su perfil- en alguno de estos centros de atención.

La concentración de las personas migrantes en lugares específicos le facilitó al Gobierno las tareas de limpieza, alimentación y atención en los servicios de salud, y a las personas migrantes les garantizaba condiciones básicas de seguridad, alimentación y resguardo. De esta manera, el Estado fue estructurando su respuesta y pasó de tener decenas de albergues dispersos a establecer centros especializados en la atención de personas migrantes, quedando instalados de forma permanente uno en la zona norte (Peñas Blancas) y otro en la zona sur (Golfito).

No obstante, la creación de estos centros especializados generó inquietudes legales y operativas. En lo legal, las autoridades se negaban a llamarle albergue, ya que obligaba al Estado a brindar atenciones y servicios que no podía garantizar, pero tampoco podían ser centros de aprehensión porque ahí permanecen detenidas las personas migrantes que están en condición irregular y esperan ser deportadas, además de que tampoco puede haber 
menores de edad. En este sentido cabe mencionar que las personas migrantes en tránsito eran indeportables por varias razones: se trataba de miles de personas, por lo que deportarlas implicaba un alto costo económico y político para el país. Asimismo, quienes tenían documentación migratoria no podían dar cuenta de su procedencia antes de llegar a Costa Rica, por lo que solo se podían deportar a Ecuador o a Cuba; y en el caso de las personas extracontinentales, la mayoría ni siquiera contaba con documentación que acreditara su verdadero origen nacional.

En este contexto, los centros de aprehensión y las deportaciones no podían ser un recurso para resolver las crisis. Ante esta disyuntiva, el Gobierno costarricense creó los CATEM como una alternativa de atención temporal, que garantizaba a las personas migrantes un espacio adecuado para la alimentación y el descanso, con condiciones de salubridad, seguridad y libre movilidad.

Ahora bien, a pesar de que los CATEM empezaron a funcionar desde el año 2016 en toldos temporales, aún hasta hoy operan en estas condiciones. Al respecto, la Defensoría de los Habitantes ha llamado la atención, ya que por sus características estos toldos no cuentan con las condiciones necesarias para responder a eventos climáticos.

[...] las carpas donadas que usamos aquí no hubieran aguantado los ventoleros ni con [el huracán] Otto, que se cayeron varias ni con esta tormenta porque igual con [la tormenta tropical] Nate tuvimos que trasladar a la gente a una escuela. Y con el Huracán Otto hubieron [sic] varios toldos que se cayeron y se perdieron. Incluso la misma gente de la Cruz Roja, Fuerza Pública y Migración, los lavaron y con ayuda de la gente los volvieron a instalar, pero ya no podemos pensar en que se arman toldos cuando entre la gente. (Defensoría de los Habitantes, comunicación personal, 11 de noviembre de 2017)

Ante este panorama, los diferentes actores consultados coinciden en que el Estado debe estructurar su respuesta, buscando superar paulatinamente la idea de un albergue temporal en sí mismo a un albergue permanente para personas que lo utilizan de forma temporal.

La respuesta del Estado no es solo construir edificios por todo el país, es darle estructura a un protocolo de atención. Si tenés el edificio divino, pero igual no está planificada la atención, ¿con qué llenas el edificio? (...) no que después de que llega el montón de gente hay que ver de dónde cogemos la comida. (Defensoría de los Habitantes, comunicación personal, 11 de noviembre de 2017)

En la actualidad, la recepción y atención de las personas se lleva a cabo a través de un protocolo que empieza desde que están en Panamá. En octubre de 2016, los gobiernos de Costa Rica y Panamá celebraron la Cumbre Binacional de Seguridad, conocida como Cumbre de Boquete, en la que suscribieron un acuerdo para organizar la llegada y el traslado de las personas migrantes. De esta manera, el Servicio Nacional de Fronteras (SENAFRONT) y la DGME organizan grupos de hasta 100 personas que trasladan semanalmente desde Panamá hacia Costa Rica en autobuses, siguiendo controles 
migratorios y en horario administrativo. Una vez en Costa Rica, las autoridades locales esperan a las personas, que para ese momento ya cuentan con información previa de su perfil (nombre, nacionalidad, edad, personas enfermas, etc.), lo cual facilita la planificación de los servicios que se les debe brindar.

Hoy en día en Costa Rica se hace un registro de las personas migrantes, siendo la DGME el organismo que toma sus datos, fotografías y huellas digitales; el Ministerio de Salud valora su condición de salud y, en caso de necesitar atención médica, la Cruz Roja les traslada al hospital, de lo contrario se les dirige hasta el CATEM de Golfito.

Actualmente en los CATEM hay traductores, se cuenta con vehículos para trasladar a las personas migrantes desde la frontera hasta el CATEM y se les brinda alimentación y resguardo, generando un sistema básico que les atiende sin impedir que sigan su camino.

En el plano normativo, el 18 de octubre de 2016 el Poder Ejecutivo emitió la "Directriz sobre la atención de personas en tránsito y condición irregular, personas objeto del tráfico ilícito de migrantes y víctimas de trata de personas, pertenecientes a los flujos migratorios mixtos que se encuentren en territorio nacional MP-MTSS-MIDEPLAN-S-MSP-RREEMDHIS-MCM", (Decreto Ejecutivo No 057 MP-MTSS-Ministerio de Planificación Nacional y Política Económica-S-MSP-RREE-MDHIS-MCM, 2016).

Esta Directriz establece lineamientos para la debida coordinación y colaboración interinstitucional para atender, de manera integral, a las personas en tránsito y en condición irregular, personas objeto del tráfico ilícito de migrantes y víctimas de trata de personas, pertenecientes a los flujos migratorios mixtos que se encuentran en el territorio nacional. (Artículo 1)

Con la firma de esta Directriz, el Gobierno amplió temporalmente algunos mandatos de las instituciones; por ejemplo, el Patronato Nacional de la Infancia (PANI) ${ }^{12}$ intervino en albergues donde había personas adultas, la DGME intervino en albergues con niñas y niños, o la $\mathrm{CNE}^{13}$ pudo generar una alerta amarilla en una emergencia que no estaba asociada con amenazas de origen natural o antrópico, lo cual facilitó el acceso a recursos económicos del fondo de emergencias para alquilar cabañas sanitarias, contratar la alimentación y darle mantenimiento a los albergues.

- Como resultado de esta Directriz, el Estado costarricense priorizó tres líneas de trabajo, definiendo competencias y delegando tareas específicas a diferentes instituciones:

- Resguardo y seguridad transfronteriza a cargo del Ministerio de Seguridad Pública.

12 Institución rectora de las políticas dirigidas a atender la niñez y la adolescencia.

13 Instancia rectora de la gestión de riesgos a desastres y atención de emergencias en el país. 
- Atención de las personas migrantes a cargo de la Caja Costarricense de Seguridad Social (CCSS), la CNE, la DGME, el Instituto Nacional de las Mujeres (INAMU), el Ministerio de Gobernación y Policía, el Ministerio de Planificación Nacional y Política Económica (MIDEPLAN), el Ministerio de la Presidencia y sus dependencias, el Ministerio de Salud (MINSA), el Ministerio de Seguridad Pública y PANI.

- En esta línea de trabajo destaca que la DGME es la responsable de asumir la coordinación operativa y técnica del trabajo interinstitucional, mientras que el Ministerio de Planificación Nacional y Política Económica asume la coordinación política.

- Abordaje migratorio regional y extrarregional a cargo del Ministerio de Relaciones Exteriores y Culto.

El artículo 5 de la Directriz señalada indica que el Fondo Especial de Migración, el Fondo Social Migratorio y el Fondo Nacional contra la Trata de Personas y el Tráfico Ilícito de Migrantes financiarán las acciones que planteen las instituciones; no obstante, cuando no se puedan utilizar los fondos mencionados, la DGME deberá solicitar recursos ordinarios del Estado.

A partir de lo anterior cabe mencionar que, de acuerdo con el ordenamiento jurídico costarricense, un Decreto Ejecutivo es un instrumento frágil; sin embargo, no se puede negar que representa una señal política importante en el autorreconocimiento del país como escenario de tránsito en el entramado migratorio regional.

\subsection{Alcances y limitaciones del marco normativo costarricense para responder a la migración de tránsito}

Como se indicó anteriormente, el marco normativo costarricense relacionado con las migraciones se ha estructurado en función de responder a la inmigración nicaragüense. Sin embargo, desde la entrada en vigencia de la actual Ley General de Migración y Extranjería, diferentes actores han llamado la atención sobre sus vacíos y debilidades para responder, incluso, a la complejidad de ese escenario migratorio. Por lo tanto, en el contexto de las migraciones en tránsito estos vacíos y debilidades también se han hecho evidentes. Por ejemplo, la legislación migratoria contempla tres tipos de visa: visa de turismo, visa consular y la visa restringida, las que de acuerdo con el origen nacional se otorga una u otra. La visa de turismo se extiende en el puesto migratorio por un plazo máximo de 90 días, ${ }^{14}$ la visa consular ${ }^{15}$ se gestiona en el consulado de Costa Rica previo a realizar el viaje

14 Esta categoría se otorga a personas provenientes de: Alemania, Andorra, Australia, Austria, Bahamas, Barbados, Bélgica, Brasil, Bulgaria, Canadá, Croacia, Chile, Chipre, Dinamarca, Emiratos Árabes Unidos, Eslovaquia, Eslovenia, España, Estado de Catar, Estados Unidos de América, Estonia, Finlandia, Francia, Hungría, Irlanda, Islandia, Israel, Italia, Japón, Letonia, Liechtenstein, Lituania, Luxemburgo, Malta, México, Montenegro, Noruega, Nueva Zelanda, Países Bajos (Holanda), Panamá, Paraguay, Polonia, Portugal, Principado de Mónaco, San Marino, Perú, Puerto Rico, Serbia, Sudáfrica, Reino de La Gran Bretaña, Irlanda del Norte, República Checa, República de Corea del Sur, República Helénica (Grecia), Rumania, Santa Sede Vaticano, Singapur, Suecia, Suiza, Trinidad y Tobago, Uruguay, Antigua y Barbuda, 
y se otorga por 30 días prorrogables a 90 días, mientras que la visa restringida ${ }^{16}$ se solicita también de forma previa ante la Comisión de Visas Restringidas y Refugio ${ }^{17}$ y también se extiende por 30 días prorrogables a 90 .

Según datos de la DGME, la mayoría de las personas de ambos movimientos migratorios debían contar con visa consular o con visa restringida para ingresar al país, sin embargo, la realidad migratoria presionaba por medidas flexibles y urgentes, con lo cual la DGME otorgó un permiso transitorio que permitía a las personas pasar por Costa Rica y salir hacia Nicaragua. Solo en el primer fin de semana de la llegada masiva de personas cubanas se giraron aproximadamente mil permisos, aunque con el cierre de la frontera nicaraguiense estos permisos dejaron de tener utilidad.

En este contexto, el Consejo Nacional de Migración (CNM) aprobó la visa de tránsito extraordinario, que permitía a las personas permanecer hasta por siete días en el país (Sesión Extraordinaria No. 017-2015) (Ministerio de Planificación Nacional y Política Económica, 2018). Sin bien esta visa no está contemplada en la Ley General de Migración y Extranjería, los artículos 9 y 11 de la misma facultan al CNM para habilitar este tipo de mecanismos extraordinarios.

Ante la permanencia extendida de las personas cubanas (de noviembre a marzo), el mismo CNM recomendó a la DGME y al Ministerio de Trabajo y Seguridad Social (MTSS) que autorizara permisos de trabajo temporales, previendo que su salida no sería inmediata y necesitarían trabajar (Sesión Ordinaria No. 001-2016). En caso de que alguna persona no contara con documentos migratorios, la DGME habilitó un documento especial para que

Belice, Bolivia, Dominica, El Salvador, Estado de Brunei, Federación Rusa, Filipinas, Fiyi, Granada, Guatemala, Guyana, Honduras, Islas Marianas del Norte, Islas Marshall, Islas Salomón, Kazajistán, Kiribati, Malasia, Maldivas, Samoa, San Cristóbal y Nieves, San Vicente y Las Granadinas, Santa Lucía, Santo Tomé y Príncipe, Seychelles, Surinam, Taiwán (Región), Tuvalu, Turquía, Ucrania, Vanuatu, Venezuela. El Salvador tiene regulaciones específicas.

15 Solicitan esta visa personas provenientes de Albania, Angola, Arabia Saudí, Argelia, Armenia, Azerbaiyán, Bahráin, Benín, Bielorrusia, Bosnia y Herzegovina, Botsuana, Burkina Faso (Alto Volta), Burundi, Bután, Cabo Verde, Camboya, Camerún, Colombia, Costa De Marfil, Comoras, Chad, Ecuador, Egipto, Gabón, Gambia, Georgia, Ghana, Guinea, Guinea Bissau, Guinea Ecuatorial, India, Indonesia, Jordania, Kenia, Kirguizistán, Kosovo, Kuwait, Lesoto, Liberia, Libia, Líbano, Madagascar, Malaui, Mali, Marruecos, Mauritania, Moldavia, Mongolia, Mozambique, Namibia, Nepal, Nicaragua, Níger, Nigeria, Omán, Pakistán, Papúa Nueva Guinea, República Árabe Saharahui (Sahara Occidental), República Centro Africana, República de Macedonia, República del Congo, República Democrática del Congo (Antes Zaire), República Popular China, República Democrática Popular de Laos, República Dominicana, Ruanda, Senegal, Sierra Leona, Sudán del Norte, Sudán del Sur, Suazilandia, Tailandia, Tanzania, Tayikistán, Timor Oriental, Togo, Túnez, Turkmenistán, Uganda, Uzbekistán, Vietnam, Yemen, Yibuti, Zambia, Zimbabue. En el caso de Nicaragua, China y Colombia hay regulaciones específicas.

16 Solicitan esta visa las personas provenientes de Afganistán, Bangladesh, Cuba, Eritrea, Etiopía, Haití, Irán, Iraq, Jamaica, Myanmar (Birmania), Palestina, República Árabe Siria, República Popular Democrática Corea del Norte, Somalia, Sri Lanka.

17 Esta Comisión está conformada por las personas titulares del Ministerio de Trabajo y Seguridad Social o su representante, el Ministerio de Seguridad y el Ministerio de Relaciones Exteriores y Culto (Artículo 49, Ley General de Migración y Extranjería). 
pudiera estar o salir del país de forma regular. Si luego la persona decidía quedarse en Costa Rica, con este mismo documento podía regularizar su situación migratoria.

De forma complementaria se crearon los "Permisos de ingreso y permanencia transitoria para la atención humanitaria de las personas extranjeras provenientes de África y/o Asia del Sur" (PIT) ${ }^{18}$ y la adenda que incluye a las personas haitianas en este beneficio. ${ }^{19}$ Para acceder a este permiso, cada persona debe firmar una declaración jurada mediante la cual da fe de que los datos que ha suministrado son reales. Según números de la DGME, en el periodo 2016-2017 se entregaron 26.154 PIT, de los cuales el 76\% correspondió a personas de origen africano, el $21 \%$ a personas de origen asiático y el $3 \%$ a personas de origen americano.

\section{Desafíos y recomendaciones para atender las transformaciones en las dinámicas migratorias}

Frente a los aprendizajes y avances conseguidos por la institucionalidad costarricense, también es necesario identificar y trabajar en los desafíos pendientes para responder de forma integral a las constantes transformaciones de las dinámicas migratorias, e incorporar estas realidades en los diferentes niveles de la política pública.

En el plano regional es fundamental diseñar una estrategia para garantizar el tránsito migratorio seguro y regularizado por Centroamérica. De esta manera cada país debe contar con un registro automatizado e interconectado que dé cuenta de la cantidad y la identidad de las personas que ingresan al país, que indique si cuentan o no con documentos de identificación, su nacionalidad (incluyendo la variable de nacionalidad desconocida y presunción de nacionalidad), sus requerimientos particulares de atención (condición de salud, si tienen o no alguna discapacidad, etc.), si salieron del país y en qué condiciones. Este registro además le permitirá a la institucionalidad de cada país asesorar adecuadamente a las personas migrantes sobre sus alternativas de regularización en caso de que decidan establecerse (La Defensoría de los Habitantes, 2018; OEA y OIM, 2016).

Para operar este registro, para brindar asistencia humanitaria y para apoyar a las personas migrantes que deciden retornar a sus países de origen, es necesario crear un procedimiento $\mathrm{y}$ un fondo regional en el que participe activamente el Sistema de Integración Centroamericano (SICA).

El otro escenario de acciones es en el ámbito nacional. Como se mencionó anteriormente, la legislación migratoria se ha direccionado hacia la inmigración laboral nicaragüense, pero otras dinámicas migratorias carecen de normativa pertinente que las regule, generando usos

18 Autorizados a través de las Resoluciones N DG-144-09-2016 y Nº DG-156-10-2016.

19 Resolución DG-178-11-2016. 
improvisados de la legislación que en muchas ocasiones dejan a las personas migrantes y a la propia institucionalidad frente a callejones sin salida.

En este sentido, las transformaciones en las dinámicas migratorias exigen mecanismos ágiles y viables por parte de la institucionalidad; por ejemplo, establecer un procedimiento para hacer funcional en términos administrativos y económicos la categoría migratoria por razones de humanidad, contemplada en la Ley General de Migración y Extranjería, para así desahogar la sobredemanda de la categoría de refugio.

En el ámbito de los desafíos institucionales, de acuerdo con las consultas realizadas en el marco de esta investigación, se identificaron los siguientes:

- Crear la infraestructura adecuada para instalar los CATEM de forma permanente, además de habilitar un CATEM en el área metropolitana, donde se puedan alojar migrantes en tránsito y solicitantes de refugio que recién llegan al país y no tienen donde permanecer.

- Garantizar el derecho a la educación de las personas menores de edad mientras están en los CATEM.

- Asumir el traslado de las personas migrantes del CATEM sur al CATEM norte para resguardar su integridad.

- Contar con suficiente personal capacitado de las diferentes instituciones, en los servicios que brinda cada CATEM. En este sentido, es necesario que todas las instituciones trabajen desde un enfoque diferenciado (enfoque de género, enfoque de protección especial, etc.) para la atención de las necesidades específicas de las poblaciones de más alto riesgo, incluyendo las necesidades de las mujeres y de las personas menores de edad (OIM, 2016).

- Contar con un banco de ADN para registrar la filiación de las personas menores de edad.

- Coordinar y articular el aporte y acompañamiento que brindan las organizaciones sociales con el fin de maximizar los recursos y servicios que ponen a disposición (La Defensoría de los Habitantes, 2018). En este sentido es importante tomar en cuenta que algunas organizaciones sociales funcionan a nivel regional o tienen contrapartes en otros países, lo que podría facilitar también la coordinación a nivel internacional.

- Facilitar -en términos administrativos y económicos- los procesos de regularización migratoria para quienes tienen arraigo en el país; por ejemplo, pareja, hijas e hijos costarricenses, y para quienes deciden quedarse en Costa Rica (La Defensoría de los Habitantes, 2018).

- Mantener mecanismos de comunicación fluidos y oportunos con las personas migrantes, para que conozcan sus derechos y obligaciones, los servicios que les puede brindar el Estado costarricense y para que estén al tanto de su situación migratoria (La Defensoría de los Habitantes, 2018). 
Ahora bien, para respaldar técnicamente la necesidad de mejoras en la legislación migratoria y en la oferta institucional, es necesario contar con un mecanismo que monitoree las constantes transformaciones que se dan en las dinámicas y en las rutas migratorias a nivel global, que lleve el pulso a la ocurrencia de desastres, crisis ambientales y conflictos bélicos, sociales y económicos que puedan generar migraciones forzadas o movimientos masivos de personas hacia o a través de Costa Rica.

Esta instancia debería funcionar como un ente técnico que asesore al CNM en la definición y actualización de las políticas migratorias. En este sentido también es relevante revisar el mandato que la Ley General de Migración y Extranjería le otorga a este Consejo, para que además de su rol político y asesor pueda asumir también un rol operativo -coadyuvado por la $\mathrm{CNE}$ - en la atención de emergencias migratorias.

Por último, es ineludible reconocer la importancia de fortalecer -en todos los nivelesprocesos de sensibilización y educación sobre la interdependencia, la integración social, las migraciones y los desplazamientos forzados. La sensibilización y la educación son herramientas fundamentales para las funcionarias y los funcionarios que prestan servicios en las instituciones públicas, pero también para la ciudadanía en general, ya que es el recurso que les permitirá adaptarse a las transformaciones migratorias que ocurren en el país y a interpretarse como sociedad en un contexto global.

\section{Reflexiones finales}

Costa Rica enfrenta importantes desafíos para visibilizar las diferentes dinámicas migratorias que ocurren en el país y para responder en términos de política y acción pública de forma oportuna y flexible.

En un breve período, de 2015 a 2016, el país enfrentó dos crisis migratorias importantes que se podían haber previsto si se hubiesen tomado en cuenta lo que sucedía en los países de América del Sur y Panamá durante los meses anteriores. Sin embargo, no fue posible leer oportunamente la situación del país en el contexto regional.

Esta dificultad de trabajar de forma articulada se constató nuevamente en la falta de respuesta internacional cuando Costa Rica acudió a diferentes foros solicitando apoyo e intermediación, sobre todo para conseguir que el Gobierno de Nicaragua abriera su frontera.

En este sentido, es urgente que el país asuma una política migratoria integral y prospectiva, que le permita responder oportunamente a la complejidad de las realidades migratorias que acontecen. En atención a las transformaciones que se han documentado, se evidencia que los cambios son una constante en las experiencias migratorias, lo cual obliga a desarrollar una mirada integral e interdependiente de las experiencias 
migratorias en el contexto global. Esta relectura debe expresarse en acciones concretas en al menos cuatro ámbitos:

- Asumir una actitud proactiva para favorecer la coordinación entre instituciones contrapartes de los países y así facilitar la optimización de recursos.

- Promover un enfoque político e institucional que reconozca las diferentes dinámicas migratorias que ocurren en el país y en la región.

- Actualizar la Ley General de Migración y Extranjería a la realidad migratoria y sus continuas transformaciones.

- Articular los esfuerzos de diferentes actores que participan en la atención de los movimientos migratorios, por ejemplo, organizaciones sociales, organismos internacionales, instituciones públicas, redes interinstitucionales, etc.

Por último, es impostergable que tanto Costa Rica como la región centroamericana se lean en un contexto migratorio regional y global que urge de miradas y medidas coordinadas para atender de forma prospectiva las constantes transformaciones que ocurren en los diferentes escenarios migratorios como países de origen, de tránsito, destino, retorno y refugio.

\section{Referencias bibliográficas}

Cavaletto, G. (2012). El terremoto de Haití 2010: Una evaluación de la respuesta humanitaria. Coordinación, financiamiento y reconstrucción. (Memoria para optar al título de Magíster en Estudios Internacionales). Universidad de Chile, Instituto de Estudios Internacionales, Chile. Recuperado de http://repositorio.uchile.cl/bitstream/handle/2250/113054/Cavaletto\%20Gilles.pdf

Ceriani, P. (2011). Luces y sombras en la legislación migratoria latinoamericana. Nueva Sociedad, (233), mayo-junio, 68-86. Recuperado de http://nuso.org/media/articles/downloads/3775_1.pdf

Chaves, M., Lexartza, L. y Carcedo, A. (2013). Procesos migratorios, integración de migrantes, derechos culturales e interculturalidad. San José, Costa Rica: CEFEMINA Programa IBER RUTAS. Recuperado de https://issuu.com/iberrutas/docs/informe-procesos-migratorios

Comitê Nacional para os Refugiados. (2017). Refugio em números. Secretaria Nacional de Justiça, Ministerio da Justiça e Segurança Pública. Recuperado de http://www.justica.gov.br/news/brasil-tem-aumento-de-12-no-numero-derefugiados-em-2016/20062017_refugio-em-numeros-2010-2016.pdf

Consejo Nacional de Migración. (2013). Política Migratoria Integral para Costa Rica. Consejo Nacional de Migración, Costa Rica. Recuperado de https://www.acnur.org/fileadmin/Documentos/BDL/2014/9485.pdf?view 
Dirección General de Migración y Extranjería. (2017). Diagnóstico del contexto migratorio de Costa Rica 2017. Recuperado de http://migracion.go.cr/integracion_desarrollo/Diagnostico\%20Contexto\%20Migrato rio\%20de\%20Costa\%20Rica\%202017.pdf

Instituto Nacional de Estadística y Censos. (2018). Encuesta Nacional de Hogares. https://www.inec.cr/

Jiménez-Matarrita, A. (2009). La vida en otra parte: migraciones y cambios culturales en Costa Rica. San José: Editorial Arlekin.

La Defensoría de los Habitantes (2018). Oficio DH-PE-080-2018. Costa Rica: autor. Recuperado de http://www.dhr.go.cr

León, G., Estrada, F., Molina, N. y Morales, A. (2012). Introducción. En A. Morales (Coord.), Migraciones y derechos laborales en Centroamérica: características de las personas migrantes y de los mercados de trabajo (pp. 3-32). San José: FLACSO.

Recuperado de http://biblioteca.clacso.edu.ar/Costa_Rica/flacso-cr/20170704035626/pdf_186.pdf

Ministerio de Planificación Nacional y Política Económica. (2018). Actualización de la Política Migratoria Integral (2013-2023) para la atención de flujos migratorios mixtos en tránsito por Costa Rica. San José: MIDEPLAN.

Nieto, C. (2014). Migración haitiana a Brasil: redes migratorias y espacio social transnacional. Buenos Aires: CLACSO. Recuperado de http://biblioteca. clacso.edu.ar/clacso/se/20141118015558/Migracion.pdf

Organización de Estados Americanos (OEA) y Organización Internacional para las Migraciones (OIM). (2016). Informe regional [sobre los] flujos de migrantes en situación migratoria irregular provenientes de África, Asia y el Caribe en las Américas. Washington D.C.: OEA-OIM. Recuperado de http://scm.oas.org/pdfs/2017/CP37161SINFORMEMIGRANTES.pdf

Organización Internacional para las Migraciones (OIM) (2006). Glosario sobre migración. Ginebra: OIM. Recuperado de https://publications.iom.int/system/files/pdf/iml_7_sp.pdf

Organización Internacional para las Migraciones (OIM) (2018a). Las tres mega tendencias del siglo XXI. [En línea]. Recuperado de http://rosanjose.iom.int/site/es/blog/lastres-mega-tendencias-del-siglo-Xxi

Organización Internacional para las Migraciones (OIM) (2018b). Informe sobre las migraciones en el mundo 2018. Ginebra: OIM. Recuperado de https://publications.iom.int/es/system/files/pdf/wmr_2018_sp.pdf

Programa Estado de la Nación (PEN). (2016). Quinto Informe Estado de la Región. [En línea]. Recuperado de https://estadonacion.or.cr/informe/?id=89555141-aef8-4341b5c0-7777d70f5b51 


\section{Legislación consultada}

Ley General de Migración y Extranjería, $N^{\circ}$ 8764, 19 de agosto de 2009. Recuperado de http://www.pgrweb.go.cr/scij/Busqueda/Normativa/Normas/nrm_norma.aspx?para $\mathrm{m} 1=\mathrm{NRM} \& \mathrm{nValor} 1=1 \& n$ Valor2=66139\&nValor3=106652\&strTipM=VS

Decreto Ejecutivo N 057 MP-MTSS-Ministerio de Planificación Nacional y Política Económica-S-MSP-RREE-MDHIS-MCM, 18 de octubre de 2006. Atención de personas en tránsito y condición irregular, personas objeto del tráfico ilícito de migrantes y víctimas de trata de personas, pertenecientes a los flujos migratorios mixtos que se encuentren en territorio nacional. Recuperado de http://www.pgrweb.go.cr/scij/Busqueda/Normativa/Normas/nrm_texto_completo.as px?param1=NRTC\&nValor1=1\&nValor2=82814\&nValor3=106066\&strTipM=TC 